\title{
Pyogenic brain abscess in children: a Tunisian multi-center experience
}

\author{
Tfifha Miniar ${ }^{1}$, Ben Abdallah Amel², Saadaoui Khalil ${ }^{3}$, Ben Helal Khaled Ben Helal ${ }^{4}$, Gueddiche \\ Med Naji Gueddiche ${ }^{5}$, Tilouche Samia Tilouche ${ }^{6}$, Hassayoun Saida ${ }^{1}$, Abroug Saoussen Abroug ${ }^{1}$
}

1. Pediatric Department, Sahloul Hospital, Sousse Tunisia, Sousse 4051 Tunisia.

2. Radiologic Department, Sousse Tunisia.

3. Neurosurgery Deaprtment, Sousse Tunisia.

4. Ibn el Jazar Hospital, Kairouan, Tunisia.

5. Fattouma Bourguiba hospital, Monastir, Tunisia.

6. Farhat Hached Hospital, Sousse, Tunisia.

\begin{abstract}
:
Background: Brain abscess (BA) is an uncommon intracranial suppurative infectious disease, especially in children. Treatment involves surgery and prolonged courses of antibiotics.

Objectives: Our study aimed to describe clinical characteristics of children with BA treated in middle Tunisian health centers.

Methods: A retrospective study lasting 19 years (1995-2014) was conducted in Tunisia middle region. Forty one children having radiologic abnormalities suggestive of BA and confirmed per operative lesions were included. Mycobacterial, parasitic or fungal abscesses were excluded. Medical records were analyzed for age, gender, presenting symptoms, predisposing factors, imaging, microbiology results, treatment and outcome.

Results: The mean age was 4.9 years. The most common clinical presentations were intracranial hypertension symptoms (87\%). BA was diagnosed in $95.1 \%$ on the basis of cranial imaging. The majority of abscesses was supra-tentorial (92.6\%). The most frequent etiology was loco-regional infections $(63.4 \%)$. No predisposing factor was found in $17 \%$. Intravenous antibiotics were given in all cases with surgical drainage in $63.4 \%$, Causative organisms were identified in $53.7 \%$. The mortality rate was $24.3 \%$. Age less than 2 years was the only statistically significant prognostic factor identified.

Conclusion: Our study confirmed the severity of this pathology and underlined the importance of early diagnosis and management.

Keywords: Pyogenic brain abscess, children, Tunisia.

DOI: https://dx.doi.org/10.4314/ahs.v18i3.13

Cite as: Miniar T, Amel BA, Khalil S, Ben Helal BHK, Gueddiche GMN, Tilouche TS, Saida H, Abroug AS. Pyogenic brain abscess in children: a Tunisian multi-center experience. Afri Health Sci. 2018;18(3): 560-568. https:// dx.doi.org/10.4314/abs.v18i3.13
\end{abstract}

\section{Background}

Brain abscess $(\mathrm{BA})$ is an uncommon intracranial suppurative infectious disease, especially when it occurs in immunocompetent children belonging to the age group of

\section{Corresponding author: \\ Tfifha Miniar, Pediatric Department. \\ Email:miniartfifha@yahoo.fr}

4-7 years ${ }^{1}$. It might cause long-term neurological deficits or even death. The diagnosis can be insidious with nonspecific clinical symptoms which depend on many factors such as age, abscess location and size ${ }^{2}$. Commonly isolated causative micro-organisms are various, with predominance of anaerobic micro-organisms. However, the microbiological spectrum has changed with increasing numbers of immune-compromised patients developing $\mathrm{BA}^{3}$. In children, the optimal management of $\mathrm{BA}$ is still controversial. The decision for surgical (excision or aspi- 
ration) versus medical treatment is debated depending on health care providers. ${ }^{3}$.

To the best of our knowledge, little is known on the situation in North Africa. The objective of this study was to characterize the features of pyogenic BA in children diagnosed and treated in Tunisian health centers and determine outcomes and prognostic factors.

\section{Patients and methods}

This is retrospectively report of all cases of children with BA treated in Tunisian middle region from January 1995 to December 2014. All patients with typical pyogenic BA on contrast computed tomography (CT) or magnetic resonance imaging (MRI) were included. We also included patients with evidence of bacterial BA uncovered by neurosurgery or appropriate microbiological specimens. Patients with a clinical history and treatment response compatible with pyogenic BA were included even when they had negative microbial findings. Mycobacterial, parasitic or fungal abscess cases and those with sub-dural empyema were excluded. The patient charts were reviewed including demographic characteristics, predisposing fac- tors, presenting symptoms, underlying medical conditions, imaging data, isolated micro-organisms, treatment and outcome. A statistical analysis of prognostic factors was realized including outcome, death and other factors (clinical, laboratory and radiology findings, and treatment modalities). Statistical data were analyzed by SPSS program. A p value less than 0.05 was considered statistically significant.

\section{Results}

Forty one children with records available for analysis were diagnosed with BA between January 1995 and December 2014. The median age was 4.9 years (range: 4 days - 16 years) and $75 \%$ were male. The patient population included 9 neonates $(21 \%)$. Forty per cent were under 2 years.

Table 1 provides major presenting symptoms and signs, more than one symptom can be found in one patient at the same time. Fever was the most common symptoms on initial presentation, noted in $58.5 \%$ of children. Headache, nausea and/or vomiting were the second most common presenting symptoms, noted in $41.4 \%$. Seizures were also a common initial presentation, noted in 14 children $(34.1 \%)$.

Table 1. Clinical signs and symptoms

\begin{tabular}{lll}
\hline Signs and symptoms & $\mathrm{N}^{\circ}$ & $\%$ \\
\hline Fever & 24 & 58.5 \\
\hline Headache & 17 & 41.4 \\
\hline Nausea-vomiting & 17 & 41.4 \\
\hline Seizures & 14 & 34.1 \\
\hline Decreased level of consciousness & 7 & 17 \\
\hline Nuchal rigidity & 9 & 21.9 \\
\hline Brudzinski sign & 6 & 14.6 \\
\hline Kernig sign & 6 & 14.6 \\
\hline hypotonia & 3 & 7.3 \\
\hline $\begin{array}{l}\text { Focal neurological involvement } \\
\text { hemiplegia }\end{array}$ & 3 & \\
\hline $\begin{array}{l}\text { Hemiparesis } \\
\text { paralysis of the upper limb }\end{array}$ & 1 & 7.3 \\
$\begin{array}{l}\text { Cranial nerve palsy } \\
\text { (facial, ocular, 6th cranial } \\
\text { palsies) }\end{array}$ & 2 & 2.4 \\
$\begin{array}{l}\text { Ataxia } \\
\text { Diplopia }\end{array}$ & 5 & 4.8 \\
\hline
\end{tabular}


Predisposing factors were identified in 34 cases $(82.9 \%)$. Twenty-six abscesses were secondary to infections involving the brain and adjacent anatomic sites including meningitis confirmed by lumbar Puncture in 18 cases $(43.9 \%)$, sinusitis in 4 cases $(12.1 \%)$, otitis media in 1 case $(2.4 \%)$, tooth abscess in 2 cases $(4.8 \%)$ and orbital cellulitis in 1 case $(2.4 \%)$. Three cases $(7.3 \%)$ occurred after head trauma. Occipital dermal sinus was identified in one case. Four BA (9.7\%) were developed in children with cyanotic congenital heart disease (CCHD) complicated in 2 cases of endocarditis and one $(2.4 \%)$ with hip arthri- tis. No predisposing factor was found in 7 cases $(17.1 \%)$. There were no cases related to immunodeficiency.

Brain CT scan was performed in all patients where MRI was realized only in 20 cases $(48.7 \%)$. BA was diagnosed by imaging in 39 (95\%). The other two patients were referred to surgery with the diagnosis of intracerebral tumor.

A single BA was detected in 33 cases (80.4\%). Frontal and parietal lobes were most commonly involved (Table 2). Three cases were presented in the temporal lobe, 2 in Parieto-occipital lobe, and 3 abscesses were located in the cerebellum (Figure 1). Eight cases had multiple BA (Figure 2).

Table 2: Abscesses localization

\begin{tabular}{lll}
\hline & $\mathrm{N}^{\circ}$ & $\%$ \\
Supratentorial & 38 & 92,7 \\
Frontal & 14 & 34.1 \\
Parietal & 7 & 17.1 \\
Temporal & 3 & 7.3 \\
Occipital & 1 & 2.4 \\
Fronto-parietal & 2 & 4.8 \\
Occipito-parietal & 2 & 4.8 \\
Occipito-temporal & 1 & 2.4 \\
Infratentorial (Cerebellum) & 3 & 7.3 \\
Multiple & 8 & 19,5 \\
\hline
\end{tabular}




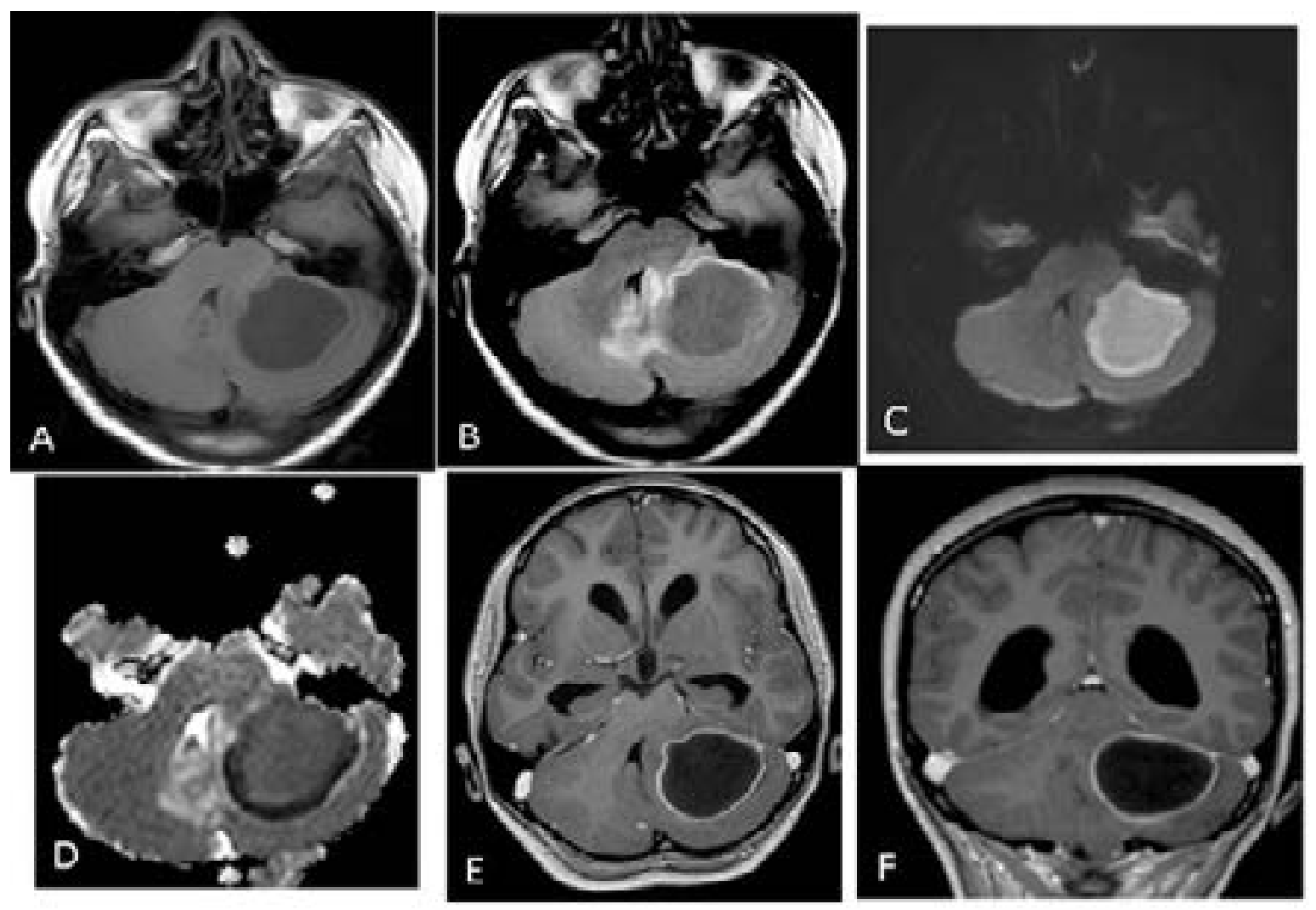

Figure 1: cerebral MRI in a 10-year-old girl with brain abscess.

A: Axial T1-weighted image before administration of contrast material shows well-defined lesion in the left cerebellum with central low intensity and isointense wall.

B: Axial fluid-attenuated inversion recovery (FLAIR) weighted image shows central high intensity with peripheral high intensity (vasogenic oedema)

C: Axial diffusio-weighted image shows marked hyperintensity in the abscess

$\mathrm{D}: A D C$ map reveals slight hypointensity, representing restricted diffusion in the corresponding region

$\mathrm{E}$ and $\mathrm{F}$ : Axial and coronal contrast-enhanced T1-weighted MR images shows a regular thin-walled ringenhanced lesion 


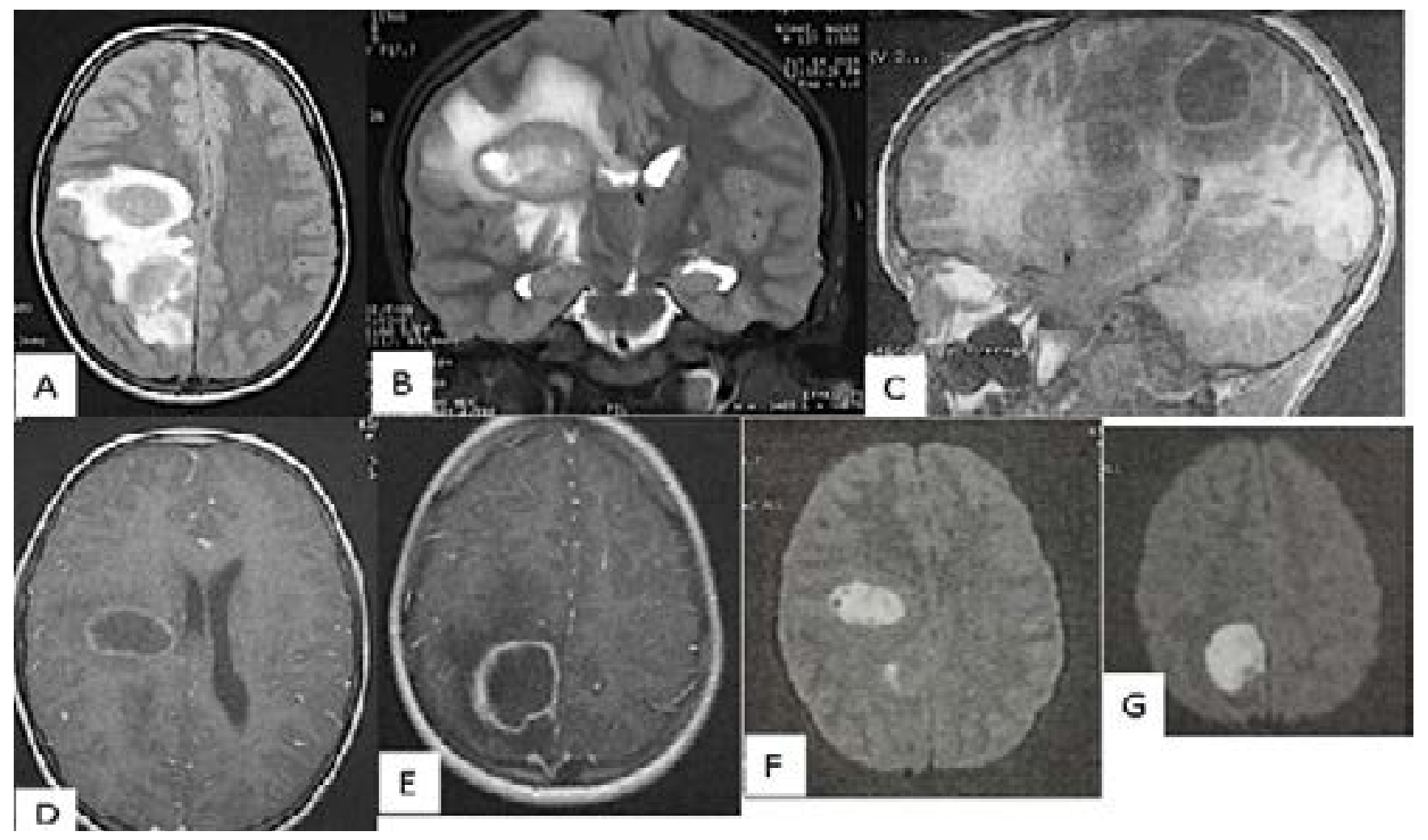

Figure 2: Cerebral MRI on a 12-year-old boy with two brain abscesses.

A, Axial fluid-attenuated inversion recovery (FLAIR) weighted image shows two nodular frontal and parietal lesions with central high intensity and peripheral high intensity representing vasogenic oedema B, Coronal T2-weighted image shows central hyperintensity with low intensity wall and peripheral vasogenic oedema

C, Sagittal T1-weighted image before administration of contrast material shows well-defined lesions with central low intensity and hyperintense wall.

D E, Axial contrast-enhanced T1-weighted MR images shows a regular thin-walled ring-enhanced lesions F G, Axial diffusion-weighted images shows marked hyperintensity in the abscesses

CT or MRI findings were corroborated by surgical intervention in only 26 patients $(63 \%)$. Surgical intervention was made immediatly at diagnosis of abscesses more than $20 \mathrm{~mm}$ diameter in 19 patients and after a few days of antibiotherapy in 7 patients. In 18 of the 26 cases (69\%), stereotactically guided aspiration was made and craniotomy excision for the others. Intravenous antimicrobial therapy alone was performed in 15 patients $(36.6 \%)$ with multiple brain abcess (six patients), deeply localized abscess (one case) and small size of the BA (8 cases). The antibiotic was parenteral in all cases.

The combination of cefotaxim, metronidazole and fosfomycin was the most commonly used treatment (34.1\%). According to the results of Gram smear and abscess aspirate cultures, the treatment was re-evaluated. Imipenem was added in three cases and ofloxacin in two cases. Parenteral treatment was prolonged for 6 weeks in 15 cases $(36.5 \%)$. Four patients $(9.7 \%)$ were treated for 4 weeks according to CT data.

Micro-organism were identified in 22 cases in different localizations $(53.7 \%)$.

Pus cultures were performed in 26 patients (64.4\%). Positive bacterial cultures were found in $14(53 \%)$ of the pus samples: Staphylococcus (6 cases), Streptococcus (3 cases) and gram negative (4 cases). Polymicrobial pathogens were isolated from one patient (Streptococus Milleri and Eikenella Corrodens) (table 3). Twenty seven patients (65.8\%) underwent lumbar puncture with 7 pathogens isolated from the cerebrospinal fluid culture (table 4). The same micro-organism was isolated in pus culture in two cases. 
Table 3. Pathogens isolated in abscess pus culture

\begin{tabular}{ll}
\hline Type of microorganisms & $\mathbf{N}^{\circ}$ of cases \\
Gram-positive cocci & \\
1. Streptococcus & \\
\hline a) S. Viridans & 2 \\
b) S. Milleri & 3 \\
c) S. pneumoniae & 1 \\
2. Staphylococcus & \\
a) S. Epidermidis & 2 \\
b) S. Aureus & 1 \\
\hline
\end{tabular}

\section{Gram-negative bacilli}

$\begin{array}{ll}\text { 1- Proteus mirabilis } & 1 \\ \text { 2-HœmophilusAphrophilus } & 1 \\ \text { 3-Citrobacter Diversus } & 1 \\ \text { 4- E. Coli } & 1 \\ \text { 5- Eikenella Corrodens } & 1\end{array}$

Table 4. Pathogens isolated in cerebrospinal fluid

\begin{tabular}{lc}
\hline Type of microorganisms & No of cases \\
\hline Gram-positive cocci & \\
\hline Streptococcus milleri & 1 \\
\hline Gram-negative cocci & \\
\hline Meningococcus & 1 \\
\hline Gram-negative bacilli & \\
1- Proteus mirabilis & 1 \\
\hline 2-Hœmophilus b & 1 \\
\hline 3-Citrobacter Diversus & 1 \\
4- E. Coli & 2 \\
\hline
\end{tabular}

Blood cultures were performed in 34 patients $(82.9 \%)$, but they were positive in only 2 cases $(5.8 \%)$, one with endocarditis and the other with hip infection.

The mortality rate was $24.4 \%$. The death was due to nosocomial infections in $40 \%$. Clinical follow-up ranged from 24 to 70 months. The patient outcomes were favorable (clinical and radiological improvement without any neurological sequel or moderate sequel with complete autonomy depending on age) in 17 patients (41.5\%) and ongoing neurological sequel in 14 patients (34.1\%).

The statistical analysis of prognostic factors showed no significant association between poor outcome, death and other factors including focal neurological deficits, fever, laboratory and radiology findings, and treatment modalities. Only age less than 2 years was identified as a statistically significant prognostic factor $(p=0.024)$. 


\section{Discussion}

The presentation of $\mathrm{BA}$ in infants is not specific ${ }^{4,5}$. Although headache, fever and vomiting, each occur in 60$70 \%$ of the patients ${ }^{6,7}$. The clinical manifestations in our patients were compatible with the results of a number of other analogous studies ${ }^{4,7-9}$.

The commonest underlying conditions in developed countries are sub-acute and chronic otitis media, mastoiditis and congenital heart disease. However, their role has declined with introduction of pneumococcal vaccination and administration of anti-microbial therapy for ear infections ${ }^{10}$. In Tunisia, pneumococcal vaccination is still not introduced into infant immunisation programmes. A predisposing factor was identified in $82.9 \%$ of our patients. In contrast to the most commonly described predisposing factors, meningitis and sinusitis were the most common predisposing factor followed by CCHD in discordance with most published reports ${ }^{1,4}$. This cannot be explain by the high rate of CCHD in our country. In fact, birth incidence of CCHD in Tunisian population is in line with the general estimates in the world. But a high rate of mortality $(23 \%)$ was reported because of medical and surgical care lack $^{11}$. Differences between studies may also be related to different patient's recruitment with 35\% of patients aged less than 2 years. In Tunisia, meningitis affects children less than two years old with relatively high frequency ${ }^{12}$.

An occipital dermal sinus, a congenital defect arising from a closure failure of the neural tube, was identified in one case. Few cases of the association with BA have been reported ${ }^{13,14}$. This underlines the importance of early detection of congenital dermal abnormalities along the craniospinal axis by routine examination of newborns ${ }^{14}$. Our patients had more frontal and parietal abscesses. This finding was similar to other studies ${ }^{1,4,15}$. The specificity of our findings is a high rate of multiple BA $(19.5 \%)$.

Negative cultures accounted for $46.3 \%$, with Sterile pus in $46 \%$. This represents a high rate of sterile cultures that has been described in others studies, ${ }^{4,16,17}$. There are different possible reasons for the high negative culture rate on our series. First, abusive antibiotic use in Tunisia is common. Secondly, the intracranial pus samples may not have been transported to the microbiology laboratory quickly enough to be successfully analyzed. Thirdly, before abscess fluid was sampled, $37 \%$ of our patients had undergone anti-microbial administration.

Nine $(22 \%)$ of our patients had pathogens including Streptococcus and Staphylococcus in the cultures. Five (12.2\%) of our patients had Gram negative bacilli, in concordance with the literature ${ }^{1,3}$. In children, the causative pathogens are aerobic and anaerobic Streptococci $(60-70 \%$ of cases), gram-negative anaerobic bacilli $(20-40 \%)$ followed by Enterobacteriaceae (20-30\%) and Staphylococcus aureus (10$15 \%)$.

Treatment of BA requires a combination of antimicrobials and surgical intervention ${ }^{7}$. Antibiotics are always necessary to manage BBA, either alone or in association with surgical intervention ${ }^{18}$.

In our study, 15 patients (36.5\%) were treated with antimicrobial therapy alone. Our ratio represents a relatively high rate of isolated medical therapy. This may be explained by the difficulty in surgical drainage for multiple, small and deeply localized BAs in Tunisian surgical department. Recent studies ${ }^{4,15}$ considered that surgical treatment should be attempted in all BA cases except during the stage of cerebritis. It not only achieves a reduction of the mass effect, but also helps in identifying infecting pathogens. Precocious culture of abscess material provided during surgery is the best opportunity to make a microbiological diagnosis ${ }^{15}$. However, surgery can be avoided by use of minimally invasive radiologic method. Aspiration of the pus can be achieved through a burr hole under CT guided stereotaxy or real-time Ultrasound ${ }^{19}$. Those modalities are not yet used in our country.

Treatment duration was usually guided by regression of abscess as verified by CT or $\mathrm{MRI}^{19}$. In our series, all patients had at least weekly follow-up neuroimaging studies. CT, a more available technique in our country in emergence condition, has proved a valuable asset in the diagnosis of BA. This imaging modality allows localization of the abscess and demonstration of any associated edema or mass effect. However, the advantages of MR imaging over CT include better differentiation of edema from liquefactive necrosis, greater sensitivity for early satellite lesions, and more sensitivity in the detection of early cerebritis ${ }^{20}$. 
There are a few recent recommendations about duration of antibiotic treatment in pediatric populations. Helweg-Larsen et $\mathrm{al}^{21}$ report no cases of recurrence in patients with postsurgical antibiotic treatment limited to less than 6 weeks. However, Sharma et $\mathrm{al}^{22}$ reported an association of short duration $(<3$ weeks) or choice of oral antibiotic therapy with recurrence of BA among eight patients. Recently, Chengyu Xia et $\mathrm{al}^{18}$ showed the short-course intravenous anti-microbial administration in the adult population can be considered to be a standard therapy for bacterial brain abscess in the surgically treated group for 10-14 days. Neuroimaging follow-up and the resolution of $\mathrm{BA}$ is a mandatory condition at the same time.

With the emergence of imaging technologies, improved microbiological techniques and prompt antibiotic and surgical management, the mortality rates reduced to $5-10 \%{ }^{23}$.The situation in Tunisia is different. In our series, we noted a high rate of mortality $(24 \%)$. The mortality directly due to $\mathrm{BA}$ in our series was $14.6 \%$, similar to other studies $^{1,4}$.

The high mortality rate is attributed to the percentage of nosocomial infection. Our findings highlight the need to intensify the fight against nosocomial infections in pediatric intensive care units especially in developing country. The duration of hospitalization increases the risk of nosocomial infection ${ }^{24}$. In according with this data, the longer duration of intravenous antibiotic therapy should be shortened. The choice between prolonged anti-microbial administration therapy with possible additive side effects and shorter duration of antibiotic therapy in children with possible higher rate of recurrence still remain controversial.

\section{Conclusion}

BA treatment is still a challenge. Predisposing factors for $\mathrm{BA}$ in children are different depending on health system development level. Mortality rate is still high in our country with high rate of nosocomial infection.

The short-course intravenous anti-microbial administration should be considered especially in developing countries like Tunisia if safety and effectiveness in the pediatric population is proven. A prospective multi-centre study is recommended for further evaluation.
The most significant determinant of poor outcome was age less than 2 years. However, the analysis of results in this case series is limited by the selection biases inherent to a retrospective study and the number of patients.

\section{Conflict of interest}

None.

\section{References}

1. Ozsürekci Y, Kara A, Cengiz AB, Celik M, Ozkaya-Parlakay A, Karadağ-Oncel E, et al. Brain abscess in childhood: a 28-year experience. Turk J Pediatr. 2012;54:144- 9. PubMed.

2. Yakut N, Kadayifci EK, Karaaslan A, Atici S, Akkoc G, Ocal Demir S, et al. Bram abscess due to Streptococcus intermedius secondary to mastoiditis in a child. Springer Plus. 2015;4. doi:10.1186/s40064-015-1608-0.

3. Zhang C, Hu L, Wu X, Hu G, Ding X, Lu Y. A retrospective study on the aetiology, management, and outcome of brain abscess in an 11-year, single-centre studyfrom China. BMC Infect Dis. 2014;14:311. PubMed. doi:10.1186/1471-2334-14-311.

4. Shachor-Meyouhas Y, Bar-Joseph G, Guilburd JN, Lorber A, Hadash A, Kassis I. Brain abscess in children - epidemiology, predisposing factors and management in the modern medicine era. Acta Paediatr Oslo Nor. 1992 2010;99:1163-7. doi:10.1111/j.1651-2227.2010.01780.x.

5. Sáez-Llorens X. Brain abscess in children. Semin Pediatr Infect Dis. 2003;14:108-14. doi:10.1053/spid.2003.127227. 6. Tsou T-P, Lee P-I, Lu C-Y, Chang L-Y, Huang L-M, Chen J-M, et al. Microbiology and epidemiology of brain abscess and sub-dural empyema in a medical center: a 10year experience. J Microbiol Immunol Infect Wei Mian Yu Gan Ran Za Zhi. 2009;42:405-12.

7. Yanai K, Oya S, Fujisawa N, Tsuchiya T, Indo M, Nakamura T, et al.A review of treatment outcomes for intracranial abscess at our institution. No Shinkei Geka. 2014;42:213-9. PubMed.

8. Brouwer MC, Coutinho JM, van de Beek D. Clinical characteristics and outcome of brain abscess: systematic review and meta-analysis. Neurology. 2014;82:806-13. PubMed. doi:10.1212/WNL.0000000000000172.

9. Brook I. Microbiology and treatment of brain abscess. J Clin Neurosci Off J Neurosurg Soc Australas. 2017;38:8-12. doi:10.1016/j.jocn.2016.12.035. 
10. Cole TS, Clark ME, Jenkins AJ, Clark JE. Pediatric focal intracranial suppuration: a UK single-center experience. Childs Nerv Syst ChNS Off J Int Soc Pediatr Neurosurg. 2012;28:2109-14. doi:10.1007/s00381-012-1877-7.

11. Abid D, Elloumi A, Abid L, Mallek S, Aloulou H, Chabchoub I, et al. Congenital heart disease in 37,294 births in Tunisia: birth prevalence and mortality rate. Cardiol Young. 2014;24:866-71. PubMed. doi:10.1017/ S1047951113001194.

12. Sfaihi L, Kamoun F, Kamoun T, Aloulou H, Mezghani S, Hammemi A, et al.Bacterial meningitis in children: epidemiological data and outcome. Tunis Med. 2014; 92:141-6. PubMed.

13. García Galera A, Martínez León MI, Pérez da Rosa S, Ros López B.Cerebellar abscesses secondary to infection of an occipital dermal sinus. Radiologia. 2013;55:4436. PubMed. doi:10.1016/j.rx.2011.01.012.

14. Groen RJ, van Ouwerkerk WJ.Cerebellar abscess caused by an occipital dermal sinus in an infant. Ned Tijdschr Geneesked. 1994;138:1575-8.

15. Radoi M, Ciubotaru V, Tataranu L. Brain abscesses: clinical experience and outcome of 52 consecutive cases. Chir Buchar Rom. 1990 2013;108:215-25. PubMed.

16. Auvichayapat N, Auvichayapat P, Aungwarawong S. Brain abscess in infants and children: a retrospective study of 107 patients in NorthEast Thailand. J Med Assoc Thail Chotmaihet Thangphaet. 2007;90:1601-7.

17. Kao K-L, Wu K-G, Chen C-J, Wu J-J, Tang R-B, Chang K-P, et al. Brain abscesses in children: analysis of 20 cases presenting at a medical center. J Microbiol Immunol Infect Wei Mian Yu Gan Ran Za Zhi. 2008;41:403-7.
18. Xia C, Jiang X, Niu C. May short-course intravenous antimicrobial administration be as a standard therapy for bacterial brain abscess treated surgically? Neurol Res. 2016;38:414-9. PubMed. doi:10.1080/01616412.2016.11 77928.

19. Frazier JL, Ahn ES, Jallo GI. Management of brain abscesses in children. Neurosurg Focus. 2008; 24:E8. doi:10.3171/FOC/2008/24/6/E8.

20. Schmidek HH. Suppurative intracranial infections. Schmidek Sweet Oper. Neurosurg. Tech. Indic. Methods Results. Philadelphia: Elsevier, Schmidek HH, Roberts DW; 2006, p. 1591-1599.

21. Helweg-Larsen J, Astradsson A, Richhall H, Erdal J, Laursen A, Brennum J. Pyogenic brain abscess, a 15 year survey. BMC Infect Dis. 2012;12:332. PubMed. doi:10.1186/1471-2334-12-332.

22. Sharma R, Mohandas K, Cooke RPD. Intracranial abscesses: changes in epidemiology and management over five decades in Merseyside. Infection. 2009;37:39-43. PubMed. doi:10.1007/s15010-008-7359-x.

23. Aras Y, Sabanci PA, Izgi N, Boyali O, Ozturk O, Aydoseli A, et al. Surgery for Pyogenic Brain Abscess over 30 Years: Evaluation of the Roles of Aspiration and Craniotomy. Turk Neurosurg. 2016;26:39- 47. PubMed. doi:10.5137/1019-5149.JTN.15099-15.1.

24. Kakupa DK, Muenze PK, Byl B, Wilmet MD.Study of the prevalence of nosocomial infections and associated factors in the two university hospitals of Lubumbashi, Democratic Republic of Congo. Pan AfrMedJ.2016;24:275. PubMed. doi:10.11604/pamj.2016.24.275.7626. 